\title{
Argyrophilic Nucleolar Organizer Regions in Hepatocytes of Focal Lesions and Background Parenchyma in Rats Treated with Peroxisome Proliferators
}

\author{
Hyoung-Chin Kim ${ }^{1,2}$, Akiyoshi Nishikawa', Fumio Furukawa', In-Seon Lee ${ }^{1,3}$, \\ Michihito Takahashi ${ }^{1}$, Toshinori Yoshida ${ }^{4}$, Takanori Harada ${ }^{4}$, \\ and Keizo Maita ${ }^{4}$ \\ ${ }^{1}$ Division of Pathology, National Institute of Health Sciences, ${ }^{2}$ Toxicology Research Center, Korea Research Institute of \\ Chemical Technology, ${ }^{3}$ Department of Food Science \& Technology, Keimyung University, and ${ }^{4}$ Toxicology Division, \\ Mitsukaido Laboratories, The Institute of Environmental Toxicology
}

\begin{abstract}
The numbers of argyrophilic nucleolar organizer regions (AgNOR) stained by the one-step silver colloid method were counted in background hepatocytes and within eosinophilic foci, amphophilic foci, and neoplastic nodules developing in rats given diet containing one of the peroxisome proliferators, clofibrate, di-(2-ethylhexyl)phthalate (DEHP), dehydroepiandrosterone (DHEA), and 4-chloro-6-(2, 3-xylidino)-2-pyrimidinylthio acetic acid (Wy-14,643), for 32 weeks after a single i.p. injection of diethylnitrosamine. The frequency of AgNORs was highest in amphophilic foci, followed by neoplastic nodules, non-lesional areas, and eosinophilic foci in the rats receiving basal diet alone or treated with clofibrate, DEHP or DHEA. In the $\mathrm{Wy}-14,643$ case the amphophilic foci and neoplastic nodules were again highest but the value for eosinophilic foci was greater over that for the background parenchyma. Mean numbers of AgNORs in non-lesional hepatocytes were elevated in rats treated with DEHP and $W y-14,643$ to 1.81 and 1.82 , respectively, significantly different $(p<0.05)$ from the control value of 1.69. The present results suggest that AgNORs may be a useful marker for predicting the hepatocarcinogenic potential of peroxisome proliferators with amphophilic foci demonstrating a particularly high proliferative activity judging from the observed AgNOR scores. (J Toxicol Pathol 1997; 10: 19 23)
\end{abstract}

Key words : AgNOR, Peroxisome proliferator, Hepatocarcinogenesis, Rat

\section{Introduction}

Tumor induction by a peroxisome proliferator was first observed in a study of nafenopin ${ }^{1}$. Subsequently a large series of chemicals have been found to cause rapid induction of peroxisome proliferation and eventual development of hepatic tumors in rats $^{2-4}$. In contrast to the unequivocal tumorigenicity of peroxisome proliferators in rodents, there is no evidence of any carcinogenicity in man, despite their widespread clinical application. To facilitate extrapolation from animal data to the risk of human cancer, we need an understanding of the mechanisms underlying carcinogenic action in animals. However, carcinogenicity of peroxisome proliferators has not been clearly explained at the molecular level.

Preneoplastic and neoplastic liver lesions induced by peroxisome proliferators are not positive for $\gamma$-glutamyl transpeptidase (GGT) ${ }^{5}$, unlike those usually associated with hepatocarcinogens. A number of studies have confirmed the lack of GGT stainability of altered foci caused by several different peroxisome proliferators, suggesting that this is a common feature of tumours developing under the infiuence of peroxisome proliferators ${ }^{6-8}$. Similarly, the preneoplastic

金 享津 西川秋佳 古川文夫 李 仁善 高橋道人 吉田敏則 原田孝則 真板敬三

Accepted for publication : November 28, 1996

Mailing address: Hyoung-Chin Kim, Toxicology Research Center, Korea Research Institute of Chemical Technology, 100 Jangdong, Yusongku, Daejon 305-343, South Korea. and neoplastic lesions which arise after administration of such chemicals are not positive for the placental form of glutathione S-transferase ${ }^{8,9}$. Therefore, recent studies have concentrated on determining the phenotype of altered foci that are relevant to tumor development due to administration of peroxisome proliferators ${ }^{10}$. These studies have demonstrated that altered foci identifiable by enzyme-histochemical reactions are relatively few in number compared to the typical lesions induced by other types of hepatocarcinogenic agents.

Recently, it has been proposed that the number and morphologic features of AgNOR in tumor cells can provide an index of biologic aggressiveness and cellular proliferative activity of a tumor ${ }^{11-19}$. In the present study, quantitation of AgNORs in hepatocytes of eosinophilic foci, amphophilic foci, and neoplastic nodules as well as background parenchyma was performed for livers of rats treated with clofibrate, di-(2-ethylhexyl)phthalate (DEHP), dehydroepiandrosterone (DHEA), or 4-chloro-6-(2, 3-xylidino)-2-pyrimidinylthioacetic acid (Wy-14,643) and the data compared with control liver values. The purpose was to examine the applicability of the AgNOR method for screening the tumorigenicity of peroxisome proliferators.

\section{Materials and Methods}

\section{Animals and chemicals}

A total of 25 male F344/DuCrj rats, were obtained at 5 weeks of age from Charles River Japan, Inc. (Kanagawa). They were acclimatized for 1 week prior to the experimenta- 


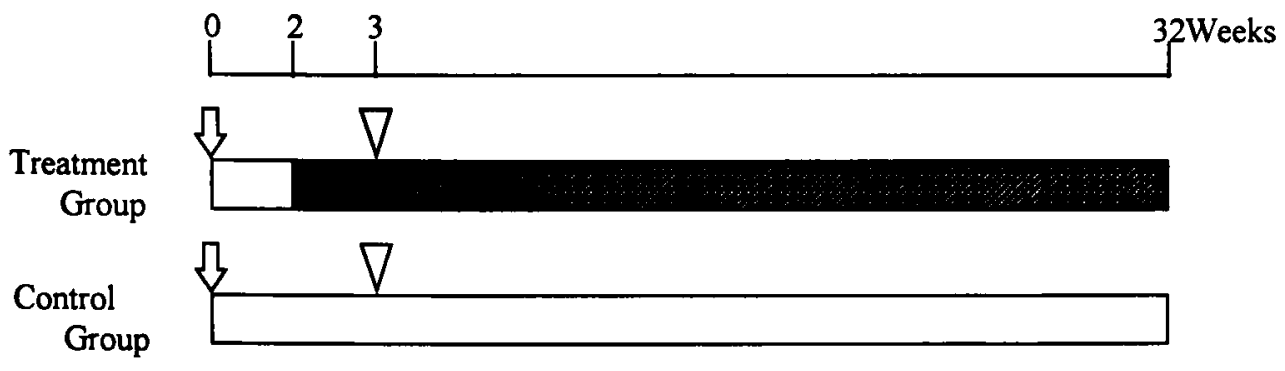

$\begin{array}{ll}\Omega & : \text { DEN (diethylnitrosamine), } 200 \mathrm{mg} / \mathrm{kg} \text { i.p. } \\ \nabla & : 2 / 3 \text { partial hepatectomy } \\ \square & : \text { basal diet } \\ & : \text { basal diet containing a test chemical }(0.3 \% \text { clofibrate, } 0.3 \% \mathrm{DEHP}, \\ & 0.45 \% \text { DEHA or } 0.01 \% \mathrm{Wy}-14,643)\end{array}$

Fig. 1. Experimental protocol used in the present experiment.

tion under standard conditions (temperature, $24 \pm 2^{\circ} \mathrm{C}$; relative humidity $55 \pm 10 \%$; illumination cycle, $12 \mathrm{~h} / 12 \mathrm{~h}$ light/ dark), and housed in stainless-steel wire cages, 5 rats per cage. Certified diet MF Mash (Oriental Yeast Co., Tokyo) and water were available ad libitum throughout the experiment. Diethylnitrosamine (DEN) and DEHP were purchased from Tokyo Kasei Kogyo Co. (Tokyo). Clofibrate, DHEA and Wy-14,643 were respectively obtained from Wako Pure Chemical Co. (Osaka), Sigma Chemical Co. (St. Louis, U.S.A.) and ChemSyn Science Lab. (Lenexsa, U.S.A.). DEHP and clofibrate were dissolved in acetone for preparation of test diets. Each of these four chemicals was incorporated into powdered basal diet using a mixer without adding oil and the prepared diets were stored in a cold room until use.

\section{Experimental protocol (Fig. 1)}

The animals were divided into 5 groups, each consisting of 5 rats, and given an intraperitoneal injection of DEN (200 $\mathrm{mg} / \mathrm{kg}$ ) dissolved in $0.9 \% \mathrm{NaCl}$ solution for the initiation of hepatocarcinogenesis. After 2 weeks on basal diet, animals were fed one of the test chemicals mixed with the basal diet or basal diet alone as the control from weeks 2 to 32 . The doses of the test chemicals were $0.3 \%$ for clofibrate and DEHP, $0.45 \%$ for DHEA and $0.01 \%$ for Wy-14,643. Partial hepatectomy was performed at week 3 .

All animals were killed at the end of week 32 when their livers were immediately excised and fixed in $10 \%$ phosphatebuffered formalin solution for routine embedding in paraffin. For histology and AgNOR staining, two serial sections were made. One section was stained with hematoxylin and eosin (HE) and the other for AgNOR using the modified one-step silver colloid method ${ }^{20}$. On AgNOR-stained slides, small black AgNOR dots in cell nuclei could be visualized by careful focusing under a light microscope at a magnification of $\times 400$. For counting the numbers of AgNORs, 80 to 150 cells in each lesion or area were analyzed. A total of 125 non-lesional areas, 104 altered foci (55 eosinophilic and 49 amphophilic), and 18 neoplastic nodules were examined. The numbers of separably discenible dots were counted, and the mean numbers of AgNORs per cell were calculated. AgNORs that were aggregated or morphologically insepa- rable were counted as one dot.

\section{Results}

\section{Body and liver weights}

Data for final body and liver weights are summarized in Table 1. Body weights were significantly decreased in the rats treated with DHEA and Wy-14,643 as compared with the control value $(\mathrm{p}<0.001$ or 0.01$)$. Liver weights were significantly increased in rats treated with clofibrate, DEHP and $W y-14,643(p<0.01$ or 0.001$)$. Liver/body weight ratios were significantly increased in rats of all treated groups $(\mathrm{p}<0.001)$.

\section{AgNORs}

The occurrence of AgNORs was most frequent in amphophilic foci, followed by neoplastic nodules, non-lesional areas, and eosinophilic foci in livers of rats treated with clofibrate, DEHP or DHEA as well as basal diet alone. The occurrence of AgNORs after Wy-14,643 treatment was most frequent in amphophilic foci, followed by neoplastic nodules, eosinophilic foci, and non-lesional areas (Fig. 2).

Data for numbers of AgNORs in nuclei of non-lesional hepatocytes are summarized in Table 2. The mean numbers of AgNORs in rats treated with DEHP and $\mathrm{Wy}-14,643$ were

Table 1. Body and Liver Weight Data

\begin{tabular}{lcccc} 
Compound & $\begin{array}{c}\text { No. of } \\
\text { rats }\end{array}$ & $\begin{array}{c}\text { Final body } \\
\text { weight }(\mathrm{g})\end{array}$ & $\begin{array}{c}\text { Absolute liver } \\
\text { weight }(\mathrm{g})\end{array}$ & $\begin{array}{c}\text { Liver/body } \\
\text { weight ratio (\%) }\end{array}$ \\
\hline Control & 5 & $357.2 \pm 31.3$ & $7.41 \pm 1.06$ & $2.07 \pm 0.13$ \\
Clofibrate & 5 & $330.4 \pm 16.5$ & $9.86 \pm 1.01^{*}$ & $2.98 \pm 0.22^{* *}$ \\
DEHP & 5 & $335.0 \pm 14.3$ & $9.55 \pm 0.54^{*}$ & $2.85 \pm 0.10^{* *}$ \\
DHEA & 5 & $241.8 \pm 16.1^{* *}$ & $8.36 \pm 0.79$ & $3.46 \pm 0.30^{* *}$ \\
Wy-14, 643 & 5 & $289.4 \pm 23.1^{*}$ & $18.21 \pm 1.62^{* *}$ & $6.29 \pm 0.17^{* *}$ \\
\hline
\end{tabular}

Each value represents a mean \pm SD.

*.** Significantly different from the control group value $(*: p<$ $\left.0.01,{ }^{* *}: p<0.001\right)$. 


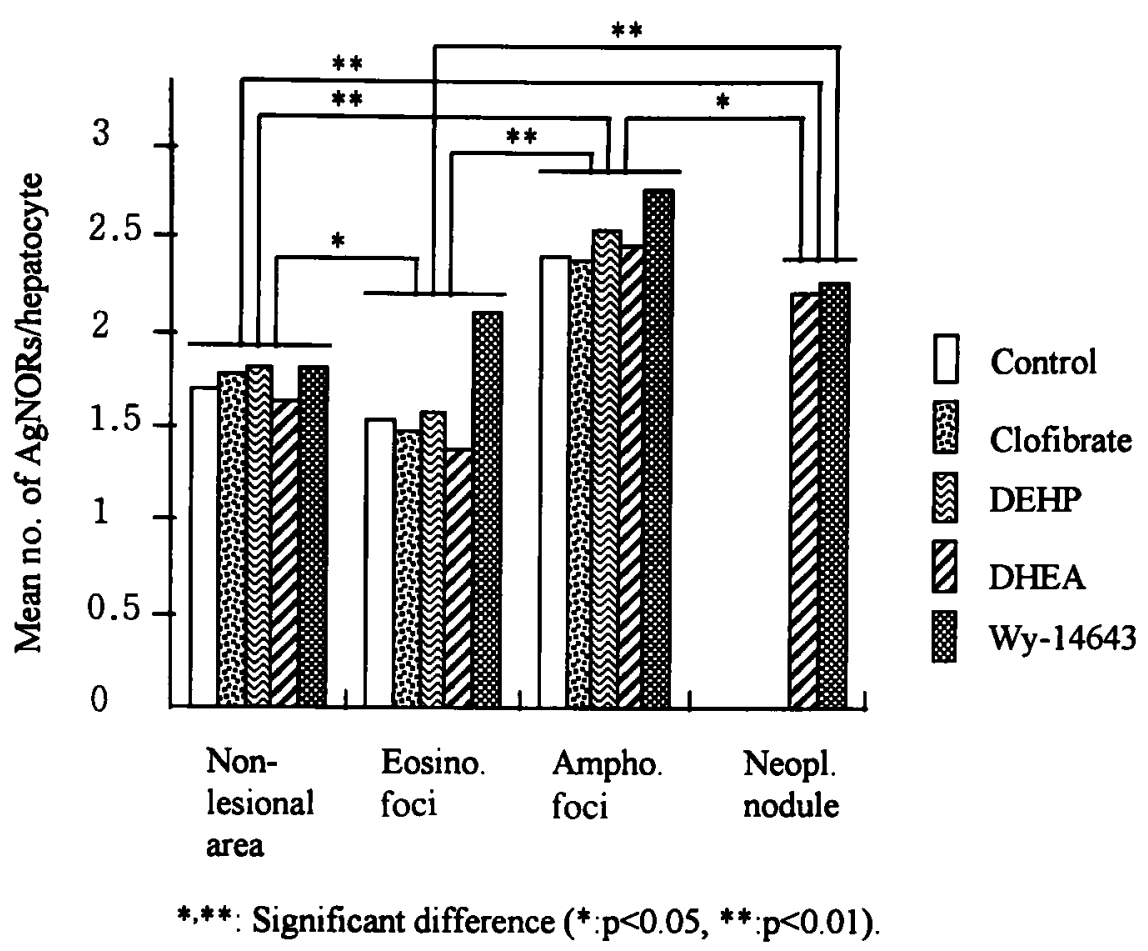

Fig. 2. Mean AgNOR numbers in hepatocytes of focal lesions and non-lesional background parenchyma.

Table 2. Number of AgNORs in Non-lesional Hepatocytes

\begin{tabular}{lccc}
\hline Compound & $\begin{array}{c}\text { No. of rats } \\
\text { examined }\end{array}$ & $\begin{array}{c}\text { No. of areas } \\
\text { examined }\end{array}$ & $\begin{array}{c}\text { No. of } \\
\text { AgNORs }\end{array}$ \\
\hline Control & 5 & 25 & $1.69 \pm 0.05^{\mathrm{a}}$ \\
Clofibrate & 5 & 25 & $1.78 \pm 0.17$ \\
DEHP & 5 & 25 & $1.81 \pm 0.06^{*}$ \\
DHEA & 5 & 25 & $1.64 \pm 0.08$ \\
Wy-14,643 & 5 & 25 & $1.82 \pm 0.07^{*}$ \\
\hline
\end{tabular}

Mean \pm SD

* Significantly different from control $(p<0.05)$.

respectively 1.81 and 1.82 , which were significantly $(\mathrm{p}<0.05)$ increased as compared with the control value (1.69).

Data for numbers of AgNORs in nuclei of lesional hepatocytes are summarized in Table 3. The mean numbers of AgNORs in amphophilic foci and neoplastic nodules were significantly $(\mathrm{p}<0.05$ or 0.01$)$ increased as compared with the values for eosinophilic foci in all groups, including the control group, with the exception of the Wy-14,643 treated group. In eosinophilic foci, the mean number of AgNORs in rats treated with DHEA was significantly $(p<0.05)$ decreased and that in rats treated with $W y-14,643$ was significantly $(p<0.05)$ increased as compared with the control value.

\section{Discussion}

Nucleolar organizer regions (NORs) are loops of ribosomal DNA that are transcribed to ribosomal RNA by RNA polymerase- $\mathrm{I}^{21}$. NORs contain genes coding for $18 \mathrm{~S}$ and 28 S ribosomal RNA, which are vitally important for the synthesis of protein ${ }^{22}$. It is well known that AgNOR scores
Table 3. Numbers of AgNORs in Focal and Nodular Lesions

\begin{tabular}{|c|c|c|c|}
\hline Group & Eosinophilic foci & Amphophilic foci & $\begin{array}{l}\text { Neoplastic } \\
\text { nodules }\end{array}$ \\
\hline Control & $1.54 \pm 0.08$ ( 4) & $2.40 \pm 0.21(4)^{* *}$ & - \\
\hline Clofibrate & $1.48 \pm 0.06(5)$ & $2.39 \pm 0.42(5)^{*}$ & - \\
\hline DEHP & $1.57 \pm 0.16(4)$ & $2.55 \pm 0.25(4)^{* *}$ & 一 \\
\hline DHEA & $1.39 \pm 0.06(5)^{\mathrm{a}}$ & $2.47 \pm 0.09(3)^{* *}$ & $2.22 \pm 0.28(4)^{* *}$ \\
\hline$W y-14,643$ & $2.11 \pm 0.29(5)^{b}$ & $2.76 \pm 0.52(5)$ & $2.27 \pm 0.10$ \\
\hline Total & $1.60 \pm 0.28$ & $2.52 \pm 0.31(21)^{\mathrm{c} * *}$ & $2.25 \pm 0.18(7)^{* *}$ \\
\hline \multicolumn{4}{|c|}{$\begin{array}{l}\text { Each value represents a mean } \pm S E \text {. } \\
\text { Numbers in parenthesis are no. of animals examined. } \\
\text { a Significantly different from eosinophilic foci of the other } \\
\text { groups }(p<0.05) \text {. } \\
\text { S Significantly different from eosinophilic foci of the other } \\
\text { groups }(p<0.05 \text { or } p<0.01) \text {. } \\
\text { c Significantly different from neoplastic nodules of the } \\
\text { group total }(p<0.05) \text {. } \\
\text { *,** Significantly different from eosinophilic foci of the } \\
\text { same group }\left(*: p<0.01,{ }^{*}: p<0.001\right) \\
\text { - No neoplastic lesions were found. }\end{array}$} \\
\hline
\end{tabular}

correlate with the transcriptional activity of ribosomal DNA $^{23,24}$, the phase in the cell cycle, and cell generation ${ }^{25}$. Thus, these histochemically demonstrable structures are linked to cellular proliferative activity. In liver disease, it has been reported that AgNOR scores for hepatocellular carcinomas are significantly higher than those for benign and borderline lesions, increasing along with the histologic tumor grade $^{18,19,26}$.

The present study has shown that the mean numbers of AgNORs in the livers of rats treated with DEHP or Wy- 
14,643 are increased as compared to the control case. This finding suggests a general enhancement of cellular proliferative activity that was not discernible in $H$ \& $E$ stained preparations. The most frequent occurrence of AgNOR was observed in amphophilic foci. Metzger et al. ${ }^{27}$ suggested that such lesions, characterized by cells exhibiting eosinophilic as well as homogeneous or somewhat scattered basophilic subcellular components ${ }^{28}$, represent a similar type of alteration as that described by Harada et al. ${ }^{29}$ as an "atypical eosinophilic focus" induced by the peroxisome proliferator 1-amino-2, 4-dibromoanthraquinone. Marsman and Popp $^{30}$ also found similar foci after long-term treatment with the peroxisome proliferator Wy-14,643, calling them "homogeneous basophilic cell foci". The available evidence thus indicates that the amphophilic foci represent precursors of hepatocellular carcinomas caused by peroxisome proliferators in rat liver. This conclusion is supported by the striking morphological similarity observed for amphophilic foci, adenomas, and carcinomas, and the similar localization of amphophilic foci and small neoplasms within the liver parenchyma $^{27}$.

In the present study, the mean number of AgNORs in neoplastic nodules was lower than that in amphophilic foci. This is reminiscent of the finding of lower percentages of BrdU-positive cells in neoplasms than in basophilic or hyperbasophilic foci induced by $\mathbf{N}$-2-fluorenylacetamide in rat liver ${ }^{26}$. Eosinophilic foci showed lower AgNOR scores than the non-lesional areas and far lower than for amphophilic foci. Thus it is suggested that the amphophilic foci may be a useful marker for hepatocellular carcinomas under the view that the AgNOR scores reflect cellular proliferation.

As shown in the present study, data for background parenchyma AgNOR staining may be a useful method for detecting carcinogenic potential induced by peroxisome proliferators in a medium-term study. Thus the AgNOR scores in non-lesional areas were increased by strongly hepatocarcinogenic peroxisome proliferators such as DEHP and Wy-14,643. However, further studies on the relationship between generalized increase in hepatocellular proliferation and development of amphophilic foci and hepatocellular carcinomas due to peroxisome proliferator exposure are required to clarify this point.

Acknowledgment : This work was supported in part by a Grant-in-Aid for Cancer Research from the Ministry of Health and Welfare, Japan.

\section{References}

1. Reddy JK and Rao MS. Malignant tumors in rats fed nafenopin, a hepatic peroxisome proliferator. J Natl Cancer Inst $1977 ; 59$ : 1645-50.

2. Reddy JK, Azarnoff DL, and Hignite CE. Hypolipidemic hepatic peroxisome proliferators form a novel class of chemical carcinogens. Nature (Lond) $1980 ; 283$ : 397-98.

3. Reddy JK and Qureshi SA. Tumorigenicity of the hypolipidemic peroxisome proliferator ethyl- $\alpha$-P-chlorophenoxyisobutyrate (clofibrate) in rats. Br J Cancer 1979; 40 : 476-82.

4. National Toxicology Program. Carcinogenesis bioassay of di(2-ethylhexyl)phthalate (CAS No. 117-81-7) in F344 rats and $\mathrm{B}_{6 \mathrm{C}} 3 \mathrm{~F}_{1}$ mice. In: NTP Technical Report Series No. 217. NIH : Bethesda, 1982.

5. Rao MS, Lalwani ND, Scarpelli DG, and Reddy JK. The absence of $\gamma$-glutamyl transpeptidase activity in putative preneoplastic lesions and in hepatocellular carcinomas induced in rats by the hypolipidemic peroxisome proliferator $\mathrm{Wy}-14$, 643. Carcinogenesis $1982 ; 3: 1231-33$.

6. Cattley RC and Popp JA. Differences between the promoting activities of the peroxisome proliferator $W y-14,643$ and phenobarbital in rat liver. Cancer Res $1989 ; 49$ : 3246-51.

7. Rao MS, Lalwani ND, and Reddy JK. Sequential histologic study of rat liver during peroxisome proliferator [4-chloro-6(2, 3-xylidino)-2-pyrimidinylthio]-acetic acid (Wy-14,643)induced carcinogenesis. J Natl Cancer Inst $1984 ; 73$ : 98390.

8. Rao MS, Tatematsu M, Subbarao V, Ito N, and Reddy JK. Analysis of peroxisome proliferator-induced preneoplastic and neoplastic lesions of rat livers for placental form of glutathione S-transferase and $\gamma$-glutamyltranspeptidase. Cancer Res $1986 ; 46: 5287-90$.

9. Ito $\mathrm{N}$, Tsuda $\mathrm{H}$, Tatematsu $\mathrm{M}$, Inoue $\mathrm{T}$, Tagawa $\mathrm{Y}$, Aoki $\mathrm{T}$, Uwagawa S, Kagawa M, Ogiso T, Masui T, Imaida K, Fukushima $S$, and Asamoto $M$. Enhancing effect of various hepatocarcinogens on induction of preneoplastic glutathione $S$ transferase placental form positive foci in rats : an approach for a new medium-term bioassay system. Carcinogenesis $1988 ; 9: 387-94$.

10. Marsman DS and Popp JA. Importance of basophilic hepatocellular foci in the development of hepatic tumors induced by the peroxisome proliferator, Wy-14,643. Proc Am Assoc Cancer Res 1989; $30: 193$.

11. Crocker $J$ and Nar $P$. Nucleolar organizer regions in lymphomas. J Pathol 1987; 151 : 111-18.

12. Deschenes $\mathrm{J}$ and Weidner $\mathbf{N}$. Nucleolar organizer regions (NOR) in hyperplastic and neoplastic prostate disease. Am J Surg Pathol 1990; 14: 1148-55.

13. Smith $\mathrm{R}$ and Crocker $\mathrm{J}$. Evaluation of nucleolar organizer region-associated proteins in breast malignancy. Histopathology $1988 ; 12$ : 113-25.

14. Albrecht S, Jambrosic JA, and Kahn HJ. Nucleolar organizer regions in superficial spreading melanoma with nodule. Mod Pathol $1989 ; 2$ : 666-70.

15. Orita T, Kajiwara K, Nishizaki T, Ikeda N, Kamiryo T, and Aoki H. Nucleolar organizer regions in meningioma. Neurosurgery $1990 ; 26: 43-46$.

16. Suarezu V, Newman J, Hiley C, Crocker J, and Collins $M$. The value of NOR numbers in neoplastic and non-neoplastic epithelium of the stomach. Histopathology $1987 ; 152$ : 8394.

17. Kram N, Nessim S, and Geller SA. A study of colonic adenocarcinoma with comparison of histopathology, DNA flow cytometric data and number of nucleolar organizer regions (NORs). Mod Pathol 1989; 2 : 468-72.

18. Crocker $\mathbf{J}$ and MacGovern $J$. Nucleolar organizer regions in normal, cirrhotic and carcinomatous liver. J Clin Pathol $1988 ; 41$ : 1044-48.

19. Nonomura A, Mizukami $Y$, Matsubara F, and Nakanuma $Y$. Identification of nucleolar organizer regions in non-neoplastic and neoplastic hepatocytes by the silver-staining technique. Liver $1990 ; 10$ : 229-38.

20. Ploton D, Menager M, Jeannesson P, Himber G, Pigeon F, and Adnet $\mathrm{JJ}$. Improvement in the staining and in the visualization of the argyrophilic proteins of the nucleolar organizer region at the optical level. Histochem J 1986; 18 : 5-14.

21. Fakan $S$ and Hernandez-Verdun D. The nucleolus and the nucleolar organizer region. Biol Cell 1986; 56: 189-206.

22. Zakharov AF, Davudov AZ, Benjush VA, and Egolina NA. Polymorphisms of Ag-stained nucleolar organizer regions in man. Hum Genet $1982 ; 60$ : 334-39.

23. Hofgartner FJ, Krone W, and Jain K. Correlated inhibition of ribosomal RNA synthesis and silver staining by actinomycin D. Hum Genet $1979 ; 47$ : 329-33. 
24. Morton CC, Brown JA, Holmes WM, Nance WE, and Wolf B. Stain intensity of the human nucleolus organizer region reflects incorporation of uridine into mature ribosomal RNA. Exp Cell Res 1983 ; 145 : 405-13.

25. Feild DH, Fitzgerald PH, and Sin FYT. Nucleolar silverstaining patterns related to cell cycle phase and cell generation of PHA-stimulated human lymphocytes. Cytobiol 1984; 41 : 23-33.

26. Tanaka $T$, Takeuchi $T$, Nishikawa A, Takami $T$, and Mori $H$ Nucleolar organizer regions in hepatocarcinogenesis induced by $\mathbf{N}$-2-fluorenylacetamide in rats : comparison with bromodeoxyuridine immunohistochemistry. Jpn J Cancer Res, 1989 ; 80 : 1947-1.

27. Metzger C, Mayer D, Hoffmann H, Bocker T, Hobe G, Benner $A$, and Bannasch $P$. Sequential appearance and ultrastructure of amphophilic cell foci, adenomas, and carcinomas in the liver of male and female rats treated with dehydroepiandrosterone. Toxicol Pathol 1995; 23 : 591-605.

28. Weber $E$ and Bannasch $P$. Dose and time dependence of the cellular phenotype in rat hepatic preneoplasia and neoplasia induced by a single oral exposure to $\mathbf{N}$-nitrosomorpholine. Carcinogenesis 1994; 15 : 1219-26.

29. Harada T, Maronpot RR, Morris RW, and Boorman GA Observations on altered hepatocellular foci in National Toxicology Program two-year carcinogenicity studies in rats. Toxicol Pathol $1989 ; 17: 690-706$.

30. Marsman DS and Popp JA. Biological potential of basophilic hepatocellular foci and hepatic adenomas induced by the peroxisome proliferator, $W y-14,643$. Carcinogenesis 1994 ; 15: $111-17$ 